Gut, 1964, 5, 230

\title{
Effect of aspirin on gastric secretion
}

\author{
ANNETTE LYNCH, HELEN SHAW, AND G. W. MILTON \\ From the Department of Surgery, University of Sydney, and \\ St. Vincent's Hospital, Sydney
}

EDITORIAL SYNOPSIS This paper provides evidence by animal work of a direct toxic action of aspirin on gastric epithelium whether the contact with the drug is from the lumen or from the circulation.

It has been known for many years that ingestion of aspirin is frequently followed by damage to the gastric mucosa. Douthwaite and Lintott (1938) and Weiss, Pitman, and Graham (1961) have observed gastroscopically haemorrhagic erosions in the stomach after administration of aspirin. The effect of aspirin on the stomach of experimental animals has been documented in a large volume of literature from 1909 when Chistoni and Lapresa noted hyperaemia and ulceration in the stomach of dogs and rabbits after oral administration of aspirin. Dodd, Minot, and Arena (1937), Barbour and Dickerson (1938), and Busacchi (1938) have all made similar observations in dogs, rats, and mice using aspirin, sodium salicylate, or methyl salicylate, given either orally or intravenously.

The mechanism by which aspirin damages the stomach is not known. The overall impression from the literature is that aspirin produces its gastric effects by increasing acidity. The evidence for this is not very strong, in either man or animals. Publications discussing this point may be roughly divided into three groups, although several papers overlap into more than one group. Group 1 comprises those reports describing a raised gastric acidity after the administration of aspirin or of salicylate, group 2 those noting no change in acidity, and group 3 depression of gastric acid after aspirin.

Reports in group 1 are those of Leichtentritt (1931), Schnedorf, Bradley, and Ivy (1936), Clark and Adams (1947), Kirsner and Ford (1955), Schneider (1957), Stubbe (1958), and Winkelman and Summerskill (1961); in group 2, those of Douthwaite and Lintott (1938), Hurst (1943), Muir and Cossar (1955), Lange (1957a), Schneider (1957), Gompertz, Schlenker, Kier, Mayoral, and Crews (1958), Rubin, Pelikan, and Kensler (1959), Winkelman and Summerskill (1961), and Davidson, Smith and Smith (1962); and in group 3 those of Klocmann (1912), Caravati and Cosgrove (1946), and Winkelman and Summerskill (1961).
The object of the present experiments was to ascertain the effect of aspirin on the gastric secretion in unstimulated and maximally histamine- stimulated cats. In addition it was hoped to relate the presence or absence of gastric damage to the secretory activity of the stomach, and in this way obtain more understanding of the mechanism of injury caused by aspirin.

MATERIAL AND METHOD

Fifty-two cats weighing between 2 and $4 \mathrm{~kg}$. were used in these experiments. The technique of obtaining the secretion from an innervated total stomach pouch has already been described (Milton, Skyring, and George 1963). The technique, in brief, consisted of anaesthetizing the cat with chloralose, ligating the pylorus, and inserting a wide-bore glass cannula into the stomach through an incision in the antrum. A catheter was inserted into a femoral vein and in animals stimulated by histamine acid phosphate a continuous slow injection of histamine was given for six hours. The dose of histamine was adequate to cause a maximal secretory response throughout the experiment, i.e., $2 \cdot 2 \mu \mathrm{g}$. histamine base $/ \mathrm{kg}$. $/ \mathrm{min}$. (Milton et al., 1963). In those animals given aspirin (powdered acid acetyl sal. B.P.) or soluble aspirin (Disprin) the dose was suspended or dissolved in $15 \mathrm{ml}$. water and injected into the lumen of the exposed stomach. One and a half hours later the incision in the antrum was made, the cannula inserted, and all the fluid remaining in the stomach allowed to escape before the test began. In one series of animals the aspirin was injected into the duodenum distal to the pyloric ligature one and a half hours before the gastric samples were obtained. During the experiment the gastric juice was allowed to drain freely into a measuring cylinder placed beneath the animal. The cylinder was changed every half hour and the volume of gastric juice measured. The acidity of each specimen was titrated, using a glass electrode $p \mathrm{H}$ meter coupled to an automatic titrator (Radiometer). Total acidity was measured by titrating to $p \mathrm{H} 8.3$ against $\mathrm{N} / 50 \mathrm{NaOH}$. Each specimen was examined for the presence of blood or mucus. The amount of blood in the specimens was recorded as trace, moderate, or severe. 
At the end of the six-hour period, the animals were killed, the stomach opened and examined for erosions or injury to the mucosa. Selected areas of the stomach showing erosions or ulceration were removed for histological examination. The remaining abdominal viscera were also examined for evidence of petechial haemorrhages. Urine in the bladder was inspected for evidence of haematuria. In those animals given aspirin into the duodenum the small bowel was examined at the end of the experiment to ascertain any mucosal injury. The animals were divided into nine series (Table 1).

TABLE I

DOSAGE OF HISTAMINE AND ASPIRIN

\begin{tabular}{lccll} 
Series & $\begin{array}{l}\text { No. of } \\
\text { Cats }\end{array}$ & $\begin{array}{l}\text { Histamine } \\
(\mu g . \text { base } \\
\mathrm{kg} \cdot \text { min.) }\end{array}$ & $\begin{array}{l}\text { Dose (g.) and Type } \\
\text { of Aspirin }\end{array}$ & $\begin{array}{l}\text { Route of } \\
\text { Administration }\end{array}$ \\
\hline I & 10 & - & - & - \\
II & 7 & - & $1 \cdot 9$, insoluble & Intragastric \\
III & 9 & $2 \cdot 2$ & - & - \\
IV & 4 & $2 \cdot 2$ & $1 \cdot 9$, insoluble & Intragastric \\
V & 4 & $2 \cdot 2$ & $0 \cdot 95$, insoluble & Intragastric \\
VI & 5 & $2 \cdot 2$ & $0 \cdot 47$, insoluble & Intragastric \\
VII & 5 & $2 \cdot 2$ & $1 \cdot 9$, soluble & Intragastric \\
VIII & 4 & $2 \cdot 2$ & $0 \cdot 95$, soluble & Intragastric \\
IX & 4 & $2 \cdot 2$ & $1 \cdot 9$, insoluble & Intraduodena
\end{tabular}

\section{RESULTS}

MORTALITY Five cats, not included in series IX, died after the instillation of aspirin into the duodenum. Death in each case occurred two hours or more after administration of aspirin.

BLOOD IN GASTRIC JUICE Of the 19 cats not given aspirin (series I and III), four showed traces of blood in the first one or two specimens, the juice from then on being clear. The blood in the early specimens evidently came from the cut edge of the stomach at the site of the cannula, because there was no sign of mucosal damage when the stomach was opened. Of the remaining 33 cats, all of which were given aspirin (series II, IV-IX), all but four had blood in some specimens. Eighteen cats bled into more than six of the 12 specimens and 12 cats bled moderately into every specimen. There was a general tendency for blood to appear or to increase as the experiment progressed. Three cats which exhibited blood throughout the experiment showed a definite increase in the amount in successive specimens. In eight animals blood first appeared in the fifth specimen and from then on all the gastric juice was heavily blood-stained. The amount of bleeding appeared to be related to the extent of mucosal damage seen at necropsy.

MACROSCOPIC GASTRIC DAMAGE There was no evidence of erosion or ulceration of the gastric mucosa in any of the animals not given aspirin (series I and III).

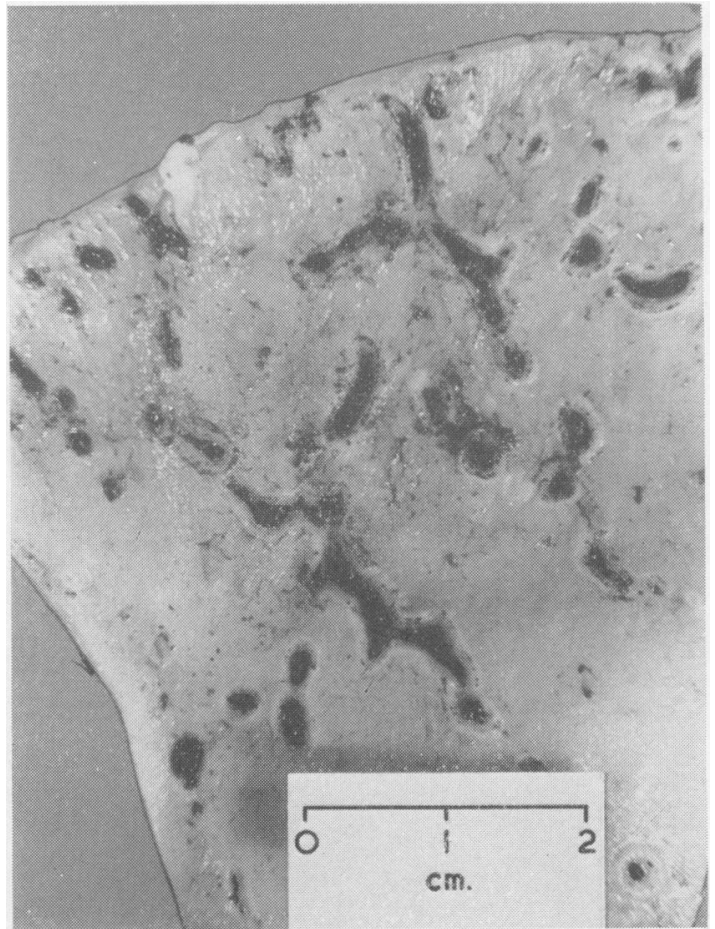

FIG. 1a. Acute gastric erosions following intragastric administration of aspirin (series VI).

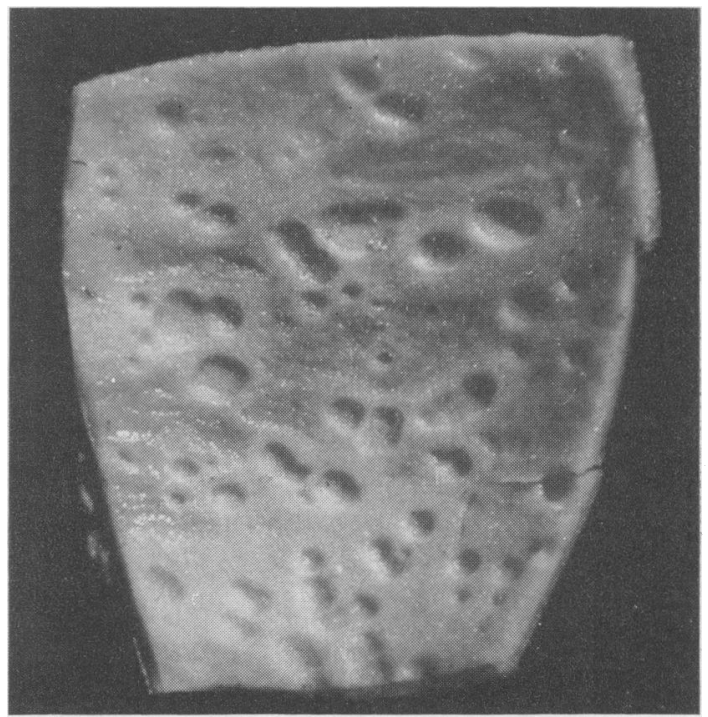

FIG. 1b. Similar acute gastric erosions seen when aspirin was injected directly into the duodenum (series $I X)$.

The gastric mucosa in all cats which were given aspirin showed some evidence of damage, and the mucosa was injured even in these animals in which 


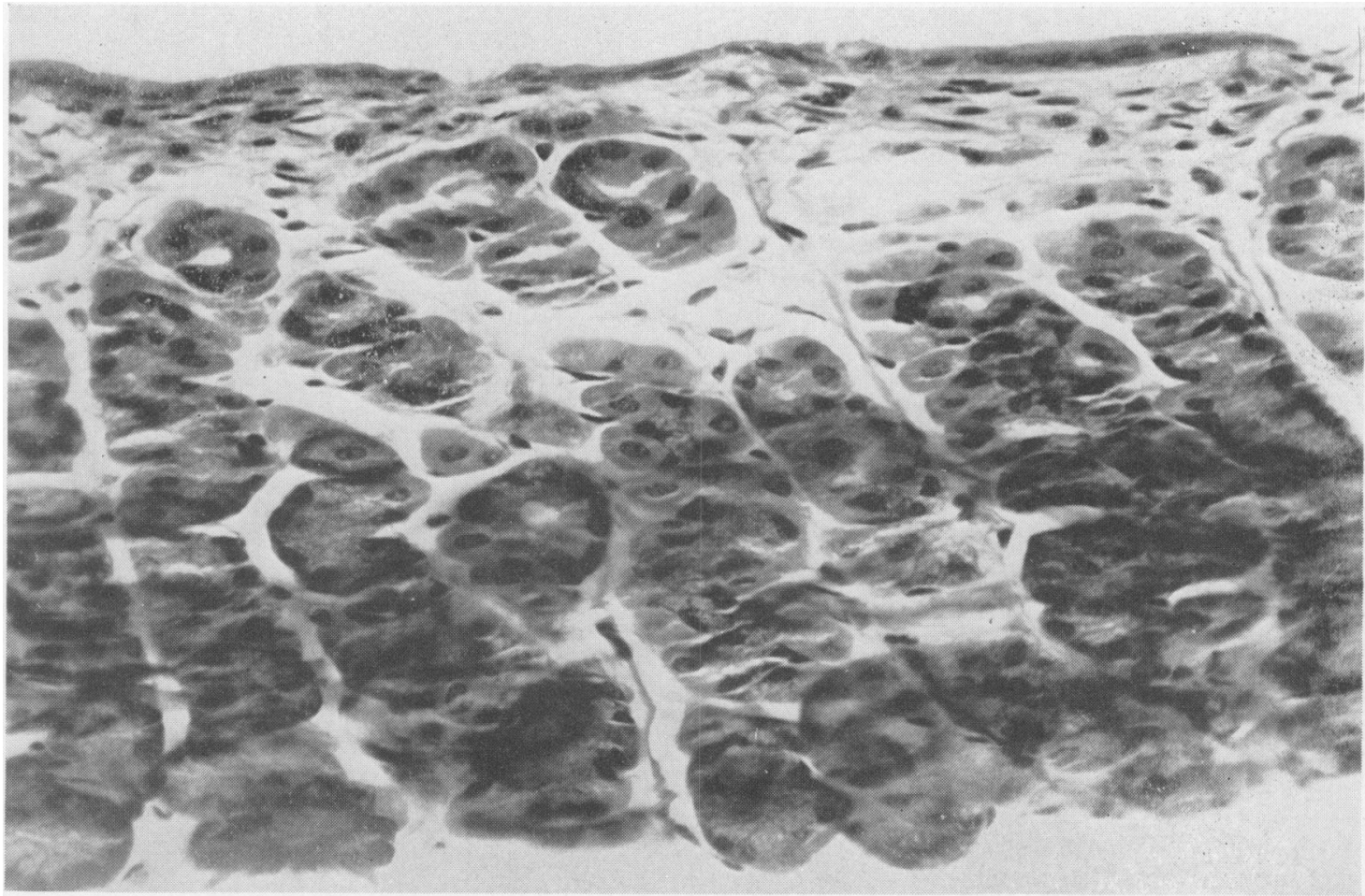

FIG. 2. Photomicrograph showing flattened surface epithelium after administration of aspirin (series IV). Note that chief and paristal cells appear normal. Haematoxylin and eosin $\times 150$.

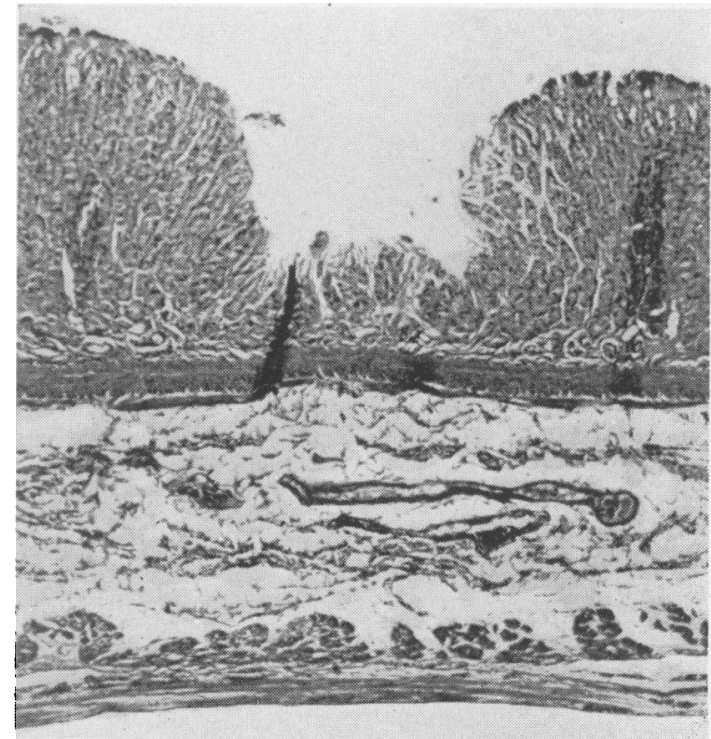

FIG. 3. Photomicrograph showing a punched-out erosion following the administration of aspirin. Note the absence of mucosal haemorrhage and the ragged appearance of the ulcer base. Haematoxylin and eosin $\times 25$. the aspirin was injected into the duodenum. This varied from a few submucosal haemorrhages to innumerable erosions and extensive submucosal haemorrhages. The lesions were evenly dispersed over the whole of the body of the stomach, but the antrum, i.e., $2-3 \mathrm{~cm}$. from the pylorus, was usually spared any severe lesion (Fig. 1a and $b$ ).

Histological examination of the stomach wall showed flattening of the normally cuboidal cells at the surface of the epithelium (Fig. 2). In the eroded areas there were patches of submucosal haemorrhage in some places, but little interstitial haemorrhage. The chief and parietal cells did not show any evidence of disintegration, but it looked almost as if the surface layers had been cut off in some sites, and the epithelium left behind was essentially normal (Figs. 2 and 3).

In the animals given aspirin directly into the duodenum (series IX) there was very little evidence of injury to the small bowel. Two of them showed small submucosal haemorrhages at the site of the needle puncture but none elsewhere. However, the stomach of all of these cats had erosions and submucosal haemorrhage similar to those in animals which received intragastric aspirin (Fig. 1b). 

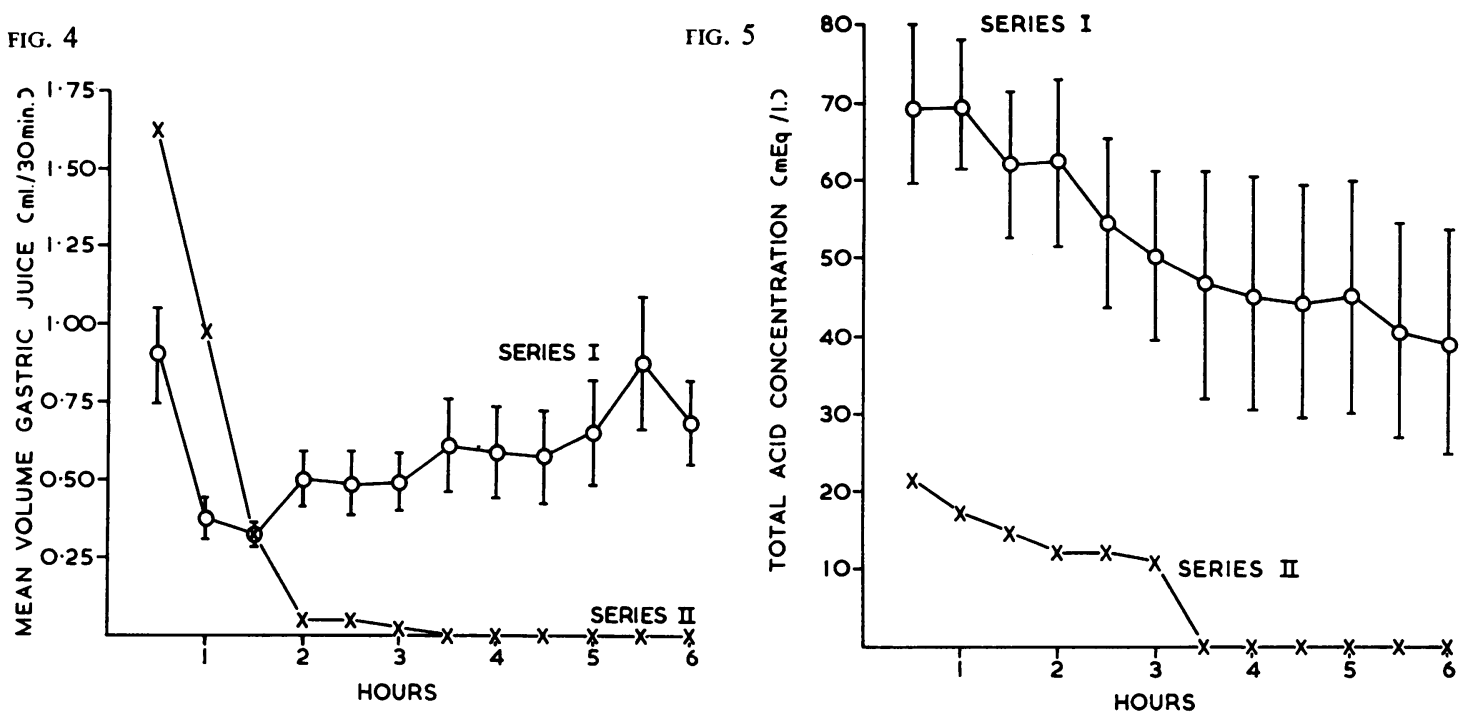

FIG. 4. The mean volume of gastric juice secreted each half hour by non-stimulated cats in series I ( $\pm S . D$. of mean) not pretreated with aspirin. Series II pretreated with $19 \mathrm{~g}$. insoluble aspirin.

FIG. 5. The mean concentration of gastric juice secreted each half hour by non-stimulated cats in series I and II ( $\pm S . D$. of mean).

The number of gastric erosions varied within each series of animals. There did not appear to be any gross difference between each series of animals concerning the extent or severity of the mucosal damage.

None of the other abdominal viscera showed evidence of subserosal or submucosal haemorrhage and in no instance was macroscopic haematuria observed.

MUCUS SECRETION There was no obvious gross difference in the mucus secretion between any of the series.

VOLUME AND ACIDITY OF GASTRIC JUICE IN NONHISTAMINE STIMULATED SERIES Figure 4 shows the volume of gastric juice secreted each half hour in series I (non-stimulated and non-aspirin treated animals) and series II (non-stimulated, aspirin $1.9 \mathrm{~g}$.). Figure 5 shows the mean concentration of acid secreted in these two series.
The volume of gastric juice secreted by those animals given aspirin was initially greater than in those not given it but within two hours the aspirintreated animals no longer secreted any appreciable amount of gastric juice. The juice secreted by the 'aspirin cats' before the cessation of gastric secretion had an average acid concentration significantly lower $(t=<0.01)$ than that of the control animals. As the small volume of secretion made it necessary to pool as many as four specimens from these animals to obtain sufficient juice for titration, it is impossible to state whether acid concentration tended to rise or fall before gastric secretion ceased.

VOLUME AND ACIDITY OF GASTRIC JUICE IN HISTAMINESTIMULATED CATS Table II shows the mean total volume, mean total acid concentration, and the mean six-hour output of acid in all histaminestimulated animals. It will be seen that in all animals pre-treated with aspirin before histamine stimulation, acidity was significantly depressed. The volume of

TABLE II

MEAN VOLUME OF GASTRIC JUICE FOR SIX HOURS, MEAN ACID CONCENTRATION, AND MEAN OUTPUT FOR SIX HOURS \pm S.D

\begin{tabular}{|c|c|c|c|c|c|c|}
\hline Series No. & $\begin{array}{l}\text { Mean Volume } \\
\text { Juice in Six Hours }\end{array}$ & $\begin{array}{l}\text { Value of } t \\
\text { Compared with } \\
\text { Series }\end{array}$ & $\begin{array}{l}\text { Mean Acid } \\
\text { Concentration } \\
\text { (mEq./l.) }\end{array}$ & $\begin{array}{l}\text { Value of } t \\
\text { Compared with } \\
\text { Series III }\end{array}$ & $\begin{array}{l}\text { Mean Acid Output } \\
\text { (ml.) in Six Hours }\end{array}$ & $\begin{array}{l}\text { Value of } t \\
\text { Compared with } \\
\text { Series III }\end{array}$ \\
\hline $\begin{array}{l}\text { III (Control) } \\
\text { IV } \\
\text { V } \\
\text { VI } \\
\text { VII } \\
\text { VIII } \\
\text { IX }\end{array}$ & $\begin{array}{l}91.8 \pm 21.9 \\
16.1 \pm 7.8 \\
24.7 \pm 12.6 \\
47.4 \pm 19.3 \\
29.7 \pm 16.9 \\
51 \cdot 3 \pm 20.1 \\
12.1 \pm 3.8\end{array}$ & $\begin{array}{l}<0.001 \\
<0 \cdot 001 \\
<0 \cdot 1 \\
<0.001 \\
<0.01 \\
<0.001\end{array}$ & $\begin{aligned} 135 & \pm 13.9 \\
50 & \pm 10 \cdot 7 \\
44 & \pm 43.2 \\
100 & \pm 16.4 \\
61 & \pm 34 \cdot 1 \\
82 & \pm 12.8 \\
87 & \pm 20.8\end{aligned}$ & $\begin{array}{l}<0.001 \\
<0.001 \\
<0.001 \\
<0.001 \\
<0.001 \\
<0.001\end{array}$ & $\begin{array}{r}13.0 \pm 3.7 \\
0.7 \pm 0.3 \\
1.6 \pm 1.3 \\
6.9 \pm 2.7 \\
2.4 \pm 1.7 \\
4.3 \pm 1.1 \\
1.1 \pm 0.5\end{array}$ & $\begin{array}{l}<0.001 \\
<0.001 \\
<0.01 \\
<0.001 \\
<0.01 \\
<0.001\end{array}$ \\
\hline
\end{tabular}


gastric juice secreted was also depressed in all aspirin-treated cats, except those in series VI $(0 \cdot 47 \mathrm{~g}$. insoluble aspirin in the stomach).

The marked inhibitory effect of aspirin on histamine-stimulated gastric juice is also shown in Figure 6. It is apparent from Fig. 6 that the smaller the dose of aspirin, the less the inhibition of secretion. Aspirin inserted in the duodenum direct (series IX) was followed by a profound inhibition of gastric secretion.

Considering the statistical difference between the inhibition produced by different doses of aspirin, there is no significant difference in the volume of gastric juice secreted between series IV, V, and IX. However, soluble aspirin (series VII and VIII) produced significantly less inhibition than insoluble aspirin at the same dosage (series IV and V) $(\mathrm{t}=$ $<0.02$ and $<0.01)$.

\section{DISCUSSION}

The results of this investigation appear to show that the damage produced by large doses of aspirin in acute experiments is largely, if not entirely, confined

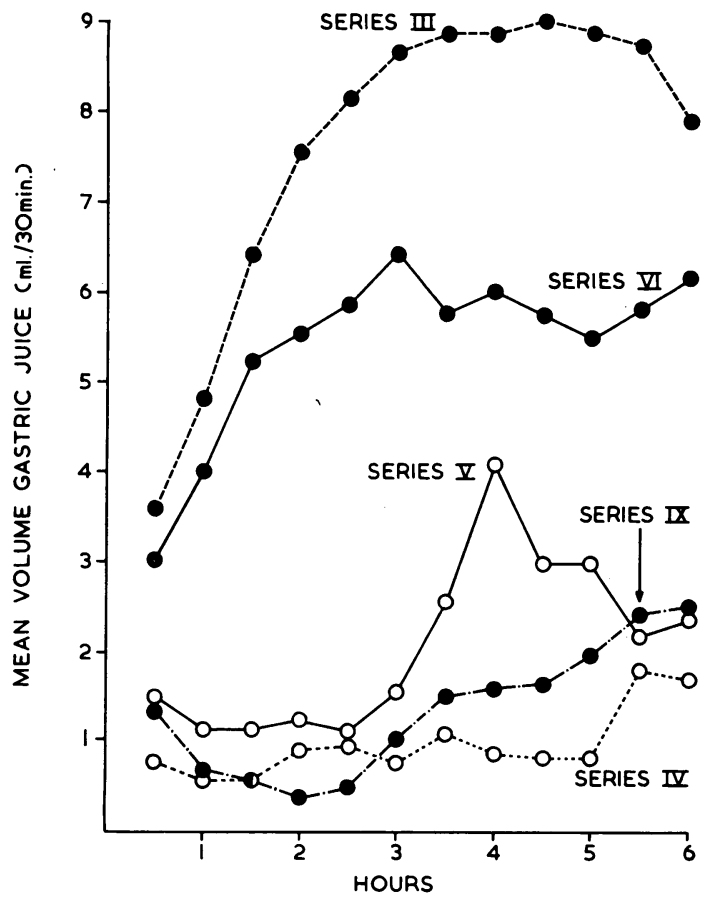

FIG. 6. The mean volume of gastric juice secreted each half hour in histamine-stimulated cats of series III (no pretreatment with aspirin). Cats of series IV were pretreated with $1.9 \mathrm{~g}$. insoluble aspirin into the stomach, series $V$ with $0.95 \mathrm{~g}$. aspirin into the stomach, series VI with $0.47 \mathrm{~g}$. into the stomach, and series IX with $1.9 \mathrm{~g}$. insoluble aspirin into the duodenum. to the stomach. Gross and Greenberg (1948) stated that in cases of salicylate poisoning petechial haemorrhages could be found in many viscera. We looked for this at necropsy, but did not find any evidence of petechial haemorrhage in other abdominal viscera. We were also unable to find any evidence to support the suggestion that a general bleeding diathesis occurred after aspirin and was responsible for gastric haemorrhage. Extensive petechial haemorrhage or haematuria would be anticipated if hypoprothrombinaemia occurred in our animals as demonstrated by Shapiro, Redish, and Campbell (1943), and Frick (1956). Later work in man has also tended to refute the belief that gastrointestinal bleeding is the result of insufficient coagulation (Muir and Cossar, 1955; Kelly, 1956; Lange, 1957b; Alvarez and Summerskill, 1958; Stubbe, 1958; Scott, Porter, Lewis, and Dixon, 1961; Pierson, Holt, Watson, and Keating, 1961).

The suggestion of Friesen, State, Jasper, Finn, and Wangensteen (1948) that aspirin induced an allergic reaction in the gut and in this way caused haemorrhage would be hard to equate with our observations. It is safe to assume that none of our animals had had aspirin before the experiments and therefore could not have an acquired sensitivity to the drug. Allergic manifestations would also have been depressed by the anaesthetic, and in addition there was no evidence of a widespread allergic reaction, e.g., bronchial spasm.

Idiosyncrasy to aspirin, postulated by some workers as an occasional cause of the gastric response to aspirin (Hurst and Lintott, 1939; Gardner and Blanton, 1940), would not apply to the many animals used in this study.

Aspirin is known to have a steroid-like effect on man (Hetzel and Hine, 1951; Houser, Clark, and Stolzer, 1954; M.R.C. 1955,; Robson and Keele, 1956; Bywaters and Thomas, 1961; Thomas, 1961). However, the effect on gastric secretion of aspirin and adrenal steroid is quite different. The steroid hormones in acute cat experiments do not produce any gross ulceration or bleeding as does aspirin, nor do they cause profound inhibition of secretion in this type of experiment (Milton, Skyring, and George, 1963).

Alvarez and Summerksill (1958) suggested that the effects of aspirin could be the result of disturbance of the central nervous system. If gross distortion of gastrointestinal blood flow occurred due to hypothalamic or sympathetic inbalance then the effects are confined to the stomach. In a deeply anaesthetized animal it seems unlikely that such effects would be pronounced. In man the gastric damage has beeen seen through the gastroscope to occur very rapidly after ingestion of aspirin before 
much absorption could take place (Douthwaite and Lintott, 1938; Hurst, and Lintott, 1939; Muir and Cossar, 1959). We have observed aspirin erosions in guinea-pigs within 20 minutes of placing aspirin solution in the stomach (Lynch and Milton, unpublished). Goodman and Gilman (1955) state that while aspirin is absorbed from the stomach it is mainly absorbed from the small intestine.

Two more theories concerning the mechanism of aspirin-produced gastric damage remain to be considered: 1 , direct mucosal irritation, and, 2, the effect of aspirin on gastric secretion. Milton et al. (1963) have shown that acute ulceration is not produced by maximal and supramaximal histamine stimulation in acute cat experiments similar to those reported here. In the present series there was no ulceration in any of the animals not given aspirin. But it was found that the animals which were given the smaller dose of aspirin had the highest gastric secretion of the treated animals and also had extensive ulceration and haemorrhage. However, the high rate of gastric secretion did not appear either to potentiate or inhibit the erosive effects of aspirin. Direct contact between aspirin and gastric epithelium certainly severely damages the epithelium. But this is not the only mechanism for damage because gastric erosions occurred in animals which were given aspirin into the duodenum after the pylorus had been ligated. This finding agrees with the observations of Dodd et al. (1937) who observed haemorrhage from the gut after intravenous sodium salicylate in dogs. Although Grossman, Matsumoto, and Lichter (1961) did not confirm this finding with sodium salicylate in man they did find increased loss of blood following intravenous aspirin. Barbour and Dickerson (1938) produced gastric ulceration in rats after repeated subcutaneous injection of aspirin and Clark and Adams (1947) demonstrated bleeding from Cope-pouch dogs after aspirin had been given orally. A high level of circulating aspirin or salicylate acid therefore appears to be an important factor in the production of gastric erosions.

Rapid absorption of aspirin causing high blood levels from an acid gastric content (Hogben, Schanker, Tocco, and Brodie, 1957; Schanker, Shore, Brodie, and Hogben, 1957) is unlikely to be the explanation of our results because all the residual aspirin had been removed from the stomach before histamine stimulation was begun. In addition the acidity of the gastric residue was very low after the aspirin had been removed (Fig. 5). The reason why circulatory aspirin or salicylate rendered the gastric epithelium friable is not clear. Many theories advanced by other workers have been discussed but none seem entirely satisfactory. Autodigestion of the stomach mucosa could be initiated by aspirin in the circulation or in the lumen. Although this theory might appear attractive, it is not likely to be correct because histological examination of the ulcers does not show autolysis deep in the glands where it would be expected if the chief and parietal cells were disintegrating.

The effect of aspirin on the gastric epithelium thus appears to be a direct toxic action, which can be produced by aspirin or derivatives in the circulation or in the gastric lumen.

\section{SUMMARY}

The effect of large doses of aspirin and soluble aspirin (Disprin) on gastric secretion and the relationship between secretion and gastric erosions have been studied in cats with a completely innervated gastric pouch. Aspirin in the large doses used profoundly inhibited the flow of stimulated and unstimulated gastric juice. The inhibition of secretion is greater with insoluble aspirin than with soluble aspirin at the same dose. Both forms of aspirin result in erosions and bleeding from the stomach. The erosions do not appear more extensive when smaller doses of aspirin are used combined with histamine stimulation and near normal acid output. Similar gastric disturbances were observed when aspirin was administered directly into the duodenum, thereby avoiding all direct contact with the stomach.

The mechanism of injury appears to be a direct toxic action of aspirin on gastric epithelium whether the contact with the drug is from the lumen or in the circulation.

It is a pleasure to acknowledge the assistance of Professor J. Loewenthal, Department of Surgery, University of Sydney, and of Professor H. O. Lancaster, Department of Mathematical Statistics, University of Sydney, for his help with the statistical evaluation of these results.

Part of the work was financed by a grant from M.C.P. Pure Drugs, Ltd., and part from the Postgraduate Committee in Medicine of the University of Sydney.

\section{REFERENCES}

Alvarez, A. S., and Summerskill, W. H. J. (1958). Gastrointestinal haemorrhage and salicylates. Lancet, 2, 920-925.

Barbour, H. G., and Dickerson, V. C. (1938). Gastric ulceration produced in rats by oral and subcutaneous aspirin. Arch. int. Pharmacodyn., 58, 78-87.

Busacchi, L. (1938). Lesioni istologiche da acido acetilsalicilico e da acetilsalicilato di sodio. Rass. Fisiopat. clin. ter. 10, 301-311.

Bywaters, E. G. L., and Thomas, G. T. (1961). Bed-rest, salicylates, and steroid in rheumatic fever. Brit. med. J., 1, 1628-1634.

Caravati, C. M., and Cosgrove, E. F. (1946). Salicylate toxicity-the probable mechanism of its action. Ann. intern. Med., 24, 638-642.

Chistoni, A., and Lapresa, F. (1909). Ricerche farmacologiche sull'aspirina. Arch. Farmacol. sper., 8, 63-80.

Clark, B. P., and Adams, W. L. (1947). The effect of acetylsalicylic acid on gastric secretion. Gastroenterology, 9, 461-465. 
Davidson, C., Smith, B. W., and Smith, P. K. (1962). Effects of buffered and unbuffered acetylsalicylic acid upon the gastric acidity of normal human subjects. J. pharm. Sci., 51, 759-763.

Dodd, K., Minot, A. S., and Arena, J. M. (1937). Salicylate poisoning; an explanation of the more serious manifestations. Amer. J. Dis. Child., 53, 1435-1446.

Douthwaite, A. H., and Lintott, G. A. M. (1938). Gastroscopic observation of the effect of aspirin and certain other substances on the stomach. Lancet, 2, 1222-1225.

Frick, P. G. (1956). Hemorrhagic diathesis with increased capillary fragility caused by salicylate therapy. Amer. J. med. Sci., 231, 402-406.

Friesen, S. R., State, D., Jasper, D. E., Finn, M., and Wangensteen, O. H. (1948). Production of allergic gastric and duodena edema which predisposes to the histamine-provoked ulcer in dogs. Surgery, 23, 167-177.

Gardner, E., and Blanton, W. B. (1940). The incidence of aspirin hypersensitivity. Amer. J. med. Sci., 200, 390-394.

Gompertz, M. L., Schlenker, F. S., Kier, J. H., Mayoral, J. W., and Crcws, J. (1958). Gastric secretory studies during prolonged salicylate administration in a comatose man. Gastroenterology, 35, 369-374.

Goodman, L. S., and Gilman, A. (1955). The Pharmacological Basis of Therapeutics, 2nd ed. Macmillan, New York.

Gross, M., and Greenberg, L. A. (1948). The Salicylates. A Critical Bibliographic Review. Hillhouse, New Haven.

Grossman, M. I., Matsumoto, K. K., and Lichter, R. J. (1961). Fecal blood loss produced by oral and intravenous administration of various salicylates. Gastroenterology, 40, 383-388.

Hetzel, B. S., and Hine, D. C. (1951). The effects of salicylates on the pituitary and suprarenal glands. Lancet, 2, 94-97.

Hegben, C. A. M., Schanker, L. S., Tocco, D. J., and Brodie, B. B. (1957). Absorption of drugs from the stomach. II. The human. J. Pharmacol exp. Ther., 120, 540-545.

Houser, H. B., Clark, E. J., and Stolzer, B. L. (1954). Comparative effects of aspirin, ACTH and cortisone on the acute course of rheumatic fever in young adult males. Amer. J. Med., 16, 168-180.

Hurst, A. (1943). (Letter to Editor). Aspirin and gastric haemorrhage. Brit. med. J., 1, 768 .

- , and Lintott, G. A. M. (1939). Aspirin as a cause of haematemesis. Guy's Hosp. Rep., 89, 173-176.

Kelly, J. J., Jr. (1956). Salicylate ingestion-a frequent cause of gastric hemorrhage. Amer. J. med. Sci., 232, 119-128.

Kirsner, J. B., and Ford, H. (1955). Phenylbutazone (Butazolidin). Effect on basal gastric secretion and the production of gastroduodenal ulcerations in dogs. Gastroenterology, 29, 18-23.

Klocmann, L. (1912). Úber die Wirkung einiger Arzneimittel auf den gesunden Magendarmkanal. Hoppe-Seylers. physiol. chem., 80, 17-34.
Lange, H. F. (1957a). Salicylates and gastric hemorrhage. I. Occult bleeding. Gastroenterology, 33, 770-777.

- (1957b). Salicylates and gastric hemorrhage. II Manifest bleeding. Gastroenterology, 33, 778-788.

Leichtentritt, B. (1931). Der akute Gelenkrheumatismus. In Handbuch der Kinderheilkunde, 4th ed., edited by $M$. von Pfaundler and A. Schlossmann, vol. 2, pp. 419-450. Vogel, Leipzig.

Milton, G. W., Skyring, A. K., and George, E. P. (1963). Histamine secretory tests in cats. Gastroenterology, 44, 642-653.

M.R.C. and Nuffield Foundation. (1955). A comparison of cortisone and aspirin in the treatment of early cases of rheumatoid arthritis. Brit. med. J., 2, 695-700.

Muir, A., and Cossar, I. A. (1955). Aspirin and ulcer. Brit. Med. J., 2, 7-12.

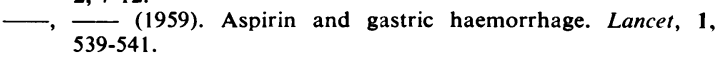

Pierson, R. N., Jr., Holt, P. R., Watson, R. M., and Keating, R. P. (1961). Aspirin and gastrointestinal bleeding. Amer. J. Med., 31, 259-265.

Robson, J. M., and Keele, C. A. (1956). Recent Advances in Pharmacology, 2nd ed. Churchill, London.

Rubin, R., Pelikan, E. W., and Kensler, C. J. (1959). Effects of unbuffered and buffered acetylsalicylic acid on intragastric $p \mathrm{H}$. New Engl. J. Med., 261, 1208-1212.

Schanker, L. S., Shore, P. A., Brodie, B. B., and Hogben, C. A. M. (1957). Absorption of drugs from the stomach. I. The rat. J. Pharmacol. exp. Ther., 120, 528-539.

Schnedorf, J. G., Bradley, W. B., and Ivy, A. C. (1936). Effect of acetylsalicylic acid upon gastric activity and the modifying action of calcium gluconate and sodium bicarbonate. Amer. J. dig. Dis., 3, 239-244.

Schneider, E. M. (1957). Aspirin as a gastric irritant. Gastroenterology, 33, 616-620.

Scott, J. T., Porter, I. H., Lewis, S. M., and Dixon, A. St. J. (1961). Studies of gastrointestinal bleeding caused by corticosteroids, salicylates, and other analgesics. Quart. J. Med., 30, $167-$ 188.

Shapiro, S., Redish, M. H., and Campbell, H. A. (1943). Studies on prothrombin. IV. The prothrombinopenic effect of salicylates in man. Proc. Soc. exp. Biol. (N. Y.), 53, 251-254.

Stubbe, L. Th. F. L. (1958). Occult blood in faeces after administration of aspirin. Brit. med. J., 2, 1062-1066.

Thomas, G. T. (1961). Five-year follow-up on patients with rheumatic fever treated by bed-rest, steroids, or salicylates. Ibid., 1, 1635-1639.

Weiss, A., Pitman, E.. R, and Graham, E. C. (1961). Aspirin and gastric bleeding. Amer. J. Med., 31, 266-278.

Winkelman, E. I., and Summerskill, W. H. J. (1961). Gastric secretion in relation to gastrointestinal bleeding from salicylate compounds. Gastroenterology, 40, 56-63. 